\title{
João Cabral de Melo Neto: imagem, concretude e rigor formal
}

\author{
William Moreno Boenavides*
}

\begin{abstract}
Resumo: Este ensaio tem a pretensão de analisar como se articulam concretude e rigor formal associados a uma precisa constituição imagética na poética cabralina. A análise terá como eixo poemas de O Engenheiro e de Quaderna. Do primeiro destacamse para objeto concreto de análise os poemas "As nuvens" e "A bailarina", através dos quais tenta-se assinalar a busca por uma precisa constituição imagética e sua articulação com a concretude, e "Pequena Ode mineral", no qual procura-se evidenciar como o elemento pedra é apresentado como horizonte a ser atingido e relaciona-se com a idéia de concretude e objetividade. Do segundo busca-se vincular, através do estudo do poema De um avião, o construtivismo dos aspectos formais às imagens propostas pelo poema, pretendendo-se ainda uma relação com a estética neoplástica de Mondrian.
\end{abstract}

Palavras-chave: João Cabral; rigor formal; imagem; artes plásticas

\begin{abstract}
This essay intends to analyze how the formal rigor and concreteness articulate when they are associated to a precise imagery construction in João Cabral de Melo Neto's poetry. The analysis is based on poems from $O$ Engenheiro and Quaderna. Through the analysis of the poems "As Nuvens", and "A Bailarina" from the first book, I try to distinguish the search for a precise imagery construction and its articulation with concreteness; and "Pequena Ode mineral", in which this study attempts to show how the element "stone" is introduced as an horizon to be reached and how it is connected to the idea of concreteness and objectivity. From the second book, the study of the poem "De um avião" attempts to link the formal aspects of the constructivism to the images proposed by the poem, as well as to show a relation with Piet Mondrian's Neo Plasticism.
\end{abstract}

Keywords: João Cabral; formal rigor; imagery; fine arts

Concretude - no sentido de materialidade, tactibilidade - e objetividade entendida como precisão matemática são duas das características da pedra destacadas e almejadas por Cabral das quais devemos captar o ensinamento. Assim, compreende-se que tratar de uma dessas marcas da poética cabralina, implica invocar as outras duas, pois há uma interdependência e articulação orgânica entre elas.

A busca pelo concreto se estabelece de forma bem acentuada já no poema "As nuvens", que abre o livro $O$ engenheiro, reunião da produção cabralina de 1942-45 que é considerado um livro de transição no qual o poeta busca clareza e racionalidade.

As nuvens são cabelos

\footnotetext{
William Moreno Boenavides é aluno do curso de graduação em Letras da Universidade Federal do Rio Grande do Sul. Atualmente o autor desenvolve o projeto "Explosão da forma: lírica e impasse de Carlos Drommond de Andrade" como aluno de Iniciação Científica sob orientação do Professor Dr. Antônio Marcos Vieira Sanseverino
} 
crescendo como rios;

são gestos brancos

da cantora muda; (MELO NETO, 2003, p.67)

Para uma constituição imagética precisa do elemento "nuvem", cujas formas são imprecisas, vagas e transitórias, são feitas comparações com elementos cujas características mais marcantes são aproveitadas para compor a imagem da nuvem. Nesse sentido, de "cabelos" é tomada a forma e possivelmente alguma relação com a consistência macia, impressão que a mobilidade (reforçada pela comparação com o rio) da nuvem transmite. Não possuindo uma constituição capaz de formar uma imagem bem definida do que ela seja, adquire aspectos de outras coisas executando assim "gestos brancos", atitude análoga a da "cantora muda", que na impossibilidade de executar o ato da fala busca outras formas de expressão para ser compreendida. Atua como elemento intensificador nessa batalha pela expressividade o uso de imagens poéticas baixas, "de sintagmas extraídos diretamente do coloquial e postos em contraste com outras áreas mais "puras" de seu vocabulário" (CAMPOS, 1967, p. 69).

Movimento idêntico, de busca por traços marcantes dos elementos para uma clara representação de um outro, encontra-se também no poema "A bailarina" do mesmo livro:

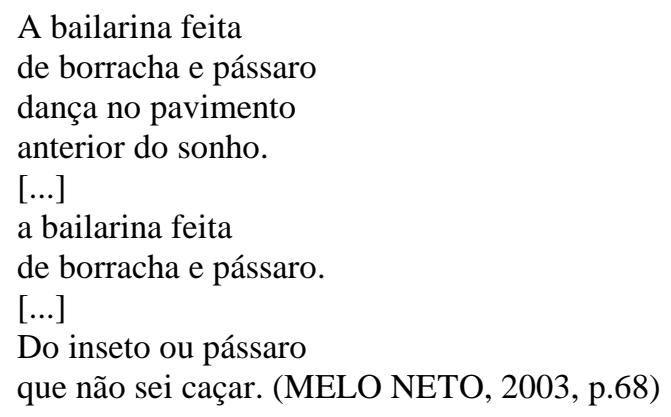

A correspondência é bem clara: a borracha, o material constitutivo da bailarina, sugere a mobilidade, a flexibilidade e do "inseto ou do pássaro" é a sugestão do movimento, da liberdade, que é buscada e que só o vôo pode dar. O elemento "inseto", nivelado com o pássaro, representa aqui a imagem baixa que provoca o contraste (a mescla conforme destacada por Auerbach) e reforça a idéia de que o que se busca representar é a liberdade do vôo, já que é esse o traço elementar que une ambos e servirá de elemento composicional representativo da liberdade da bailarina. O uso de "pavimento", termo que se associa a estruturas concretas (um andar de edifício, por exemplo), para referir-se a um intervalo de tempo, a um momento do dia, o "anterior ao sono", invoca a concretude que o uso de termos como "período" não alcançaria.

A pedra como horizonte a ser atingido é bem delineado no "Pequena Ode Mineral", último poema do mesmo livro, articulando a idéia de criar ao trabalho de um matemático. 
Esse poema "compõe-se de duas seções paralelas, cada uma contendo seis quadras. Nelas, Cabral desenvolve a antítese entre a natureza transitória da existência física e psíquica e a durabilidade da pedra" (PEIXOTO 1983, p. 49). Nota-se claramente a estrutura "pensamenteada" do poema assim como a busca pelas qualidades da pedra a serem buscadas pelo homem:

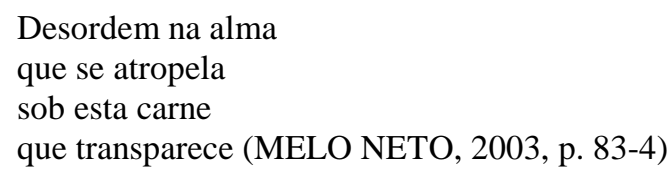

$\mathrm{Na}$ primeira estrofe tem-se a desordem da alma humana que não permite que ela possua constância e estabilidade necessárias para "penetrar nas profundezas de outra substância" (PEIXOTO, 1983, p. 51). Problemática cuja resolução - apresentada na segunda seção - deve ser encaminhada através do aprendizado de características da pedra, especialmente a ordem e o silêncio, que garantiram as almejadas ordem e estabilidade, possibilitando que a "mensagem" surta efeito, seja ouvida:

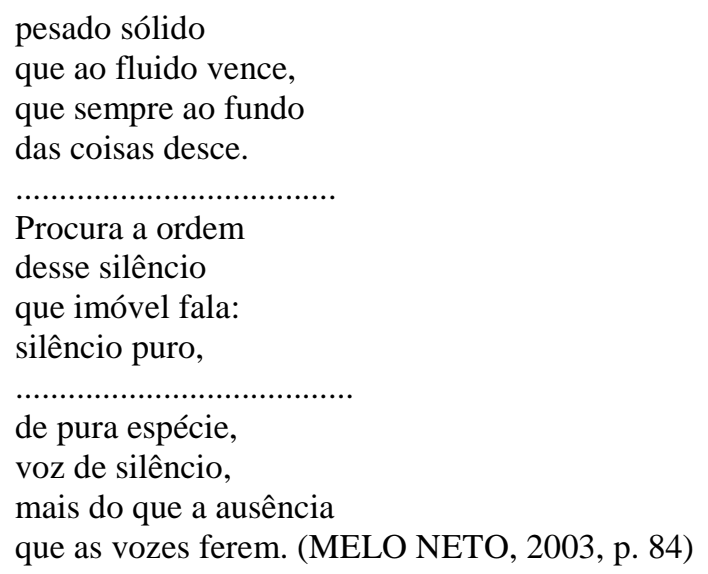

A pedra, ordenada, estável e muda é capaz de se impor com força e com sua simples presença ensina mais ao homem que o palavreado sem utilidade, desnecessário. Ampliando a significação da lição dada pela pedra nota-se que "Cabral parece referir-se também a sua própria estética de economia verbal, de eliminação rigorosa e, por extensão, de uma economia que fala" (PEIXOTO, 1983, p.51). A não-musicalidade da poesia cabralina aumenta sua força enquanto crítica social (tendência marcante a partir de $O$ cão sem plumas) e prova que a ausência gera significados e conhecimento. Corrobora para isso o fato de a lírica - ou "antilírica" - cabralina confrontar-se diretamente com nossa tradição, que não dispensa a musicalidade nem mesmo quando busca o engajamento mais acentuado, como em Drummond.

O livro Quaderna (1956-59) contém inúmeros poemas aos quais se pode referir ao abordar o processo de criação de João Cabral. Apresenta-se de forma matemática, ou mais 
precisamente, geometricamente estruturado. Quase a totalidade dos poemas que compõem o livro é formada por quartetos, forma que remete, obviamente, ao número quatro, a um quadrado, ou seja, ao que possui equilíbrio perfeito, onde nada sobra nem falta, cada parte possui seu correspondente.

O poema "De um avião" apresenta uma estrutura que se assemelha a uma engenhosa figura geométrica. Cinco partes numeradas com oito quadras cada, compondo, portanto, um total de quarenta estrofes. A quadra deve ser entendida aqui "como um bloco, como unidadeblocal de composição, elemento geométrico pré-construído, definido e apto conseqüentemente para a armação do poema" (CAMPOS, 1967, p.70). Associando-se a essas formas quadriculares, o poema constrói uma imagem composta de círculos concêntricos, formando um espiral:

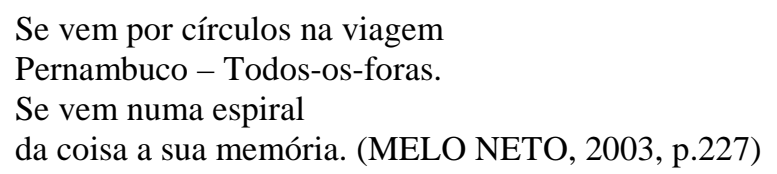

Cada parte do poema corresponde a um círculo que se afasta temporal e espacialmente do ponto de partida. "A relação de posição - a relação retangular - é indispensável para expressar o imutável em oposição com as relações variáveis da dimensão. A neoplástica procura expressar o variável e o invariável simultaneamente e em equivalência" (apud CAMPOS, 1967, p. 73).

Do primeiro "aos círculos derradeiros", a imagem fica cada vez mais distante, não só no sentido físico, mas também no social:

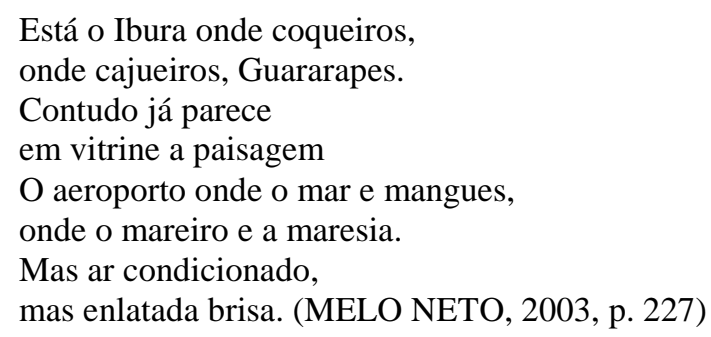

O estar em um avião já é um afastamento em relação a seus conterrâneos, que não podem sentir a "enlatada brisa", pois, em contrapartida, têm a experiência de contato direto com a natureza. A paisagem formada pela natureza é avistada como em uma vitrine, reforçando o distanciamento pela oposição Eu civilizado, vida artificial versos conterrâneos, vida natural.

Mesmo que haja todo esse afastamento, a memória e o sentido crítico se esforçam para fazer a viagem contrária, pois buscam recompor aquilo que o afastamento não permite que seja notado pelos sentidos, o vôo segue:

$\mathrm{O}$ vôo agora mais alto 


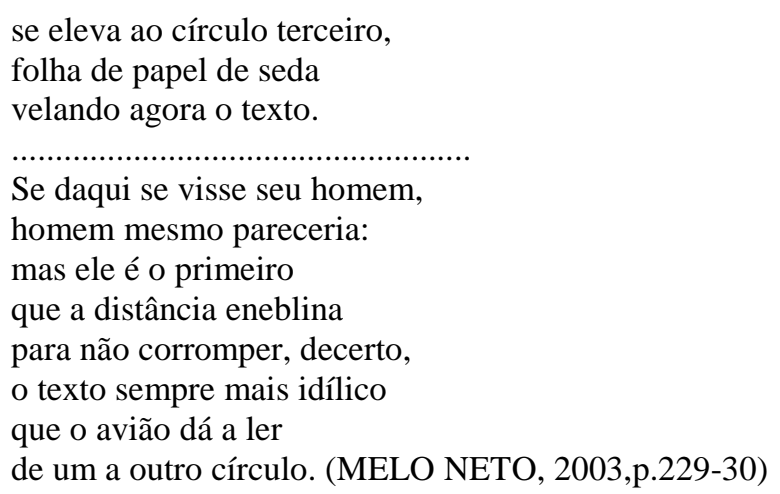

O homem, que só parece homem a distância, corromperia a imagem (que é comparada com o texto) que se forma progressivamente mais afastada. Os elementos que corrompem a escrita são trazidos e colocadas no poema, numa clara declaração de "engajamento", até que o afastamento faz com que, ao final da viagem:

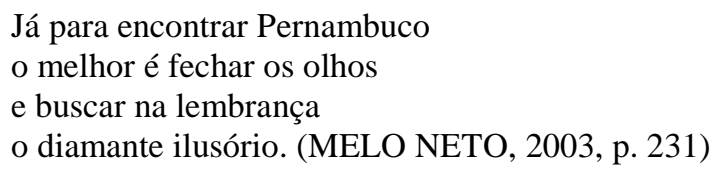

O diamante é a imagem de "todas as cores / das coisas que são Pernambuco". E o esforço do Eu lírico tensiona-se com sua realidade afastada do homem pernambucano a quem busca e só consegue encontrar quando se afasta e faz o movimento inverso do feito pela viagem:

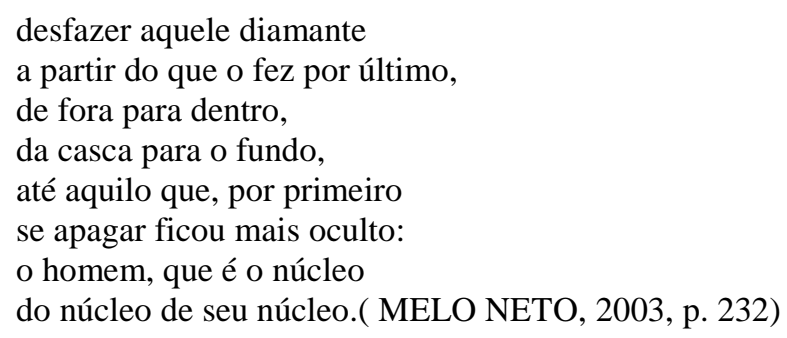

Nota-se o referido ideário neoplástico de Mondrian, que também trabalhava com a noção de eliminação dos elementos supérfluos, irrelevantes, na relação variável do ponto de vista que se altera continuamente com a forma fixa sobre a qual cada parte está estruturada. Além disso, o movimento de rememoração forma outro par, invariável-variável, com o objeto último da rememoração, o núcleo do homem estagnado em sua condição social. 


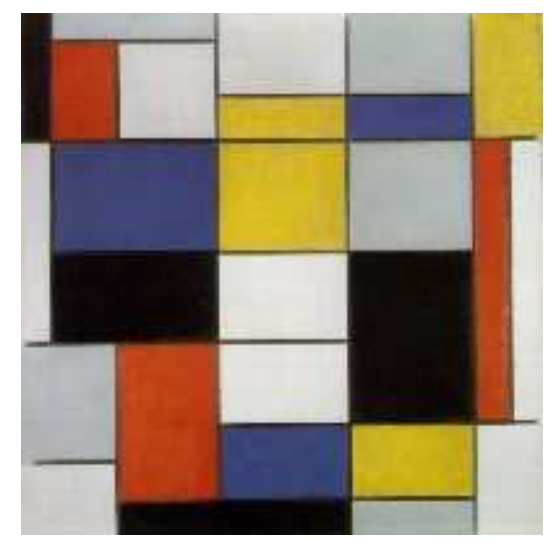

Figura 1 - Composição com preto, vermelho, cinza, amarelo e azul (1920) (http://www.artchive.com/artchive/M/mondrian/mondrian_composition_a.jpg.html)

Mondrian (1920) submete a variação das cores e o dinamismo das formas a suas grades (Fig. 1) que atuam contendo a mutabilidade em uma estrutura imutável. "A angústia diante da vida e da contemplação, na qual o tempo pára e todo barulho se interrompe, sela a obra de Mondrian.” (BONFAND, p. 34, 1994). O preto, o vermelho, o cinza, o amarelo e o azul compõem com os retângulos e quadrados de diferentes tamanhos o que seria a desordem cabralina e as grades, a forma, a quadra, que controla a variabilidade, "interrompe o barulho", ordenando o mundo e combatendo a angústia causada pelo sentimento de descontrole, das quais as formas imprecisas são o maior sinal.

Destaca-se o construtivismo do poema que expõe em cada parte a visão, a partir de um ponto de vista diferente, com clareza e objetividade obtidas com a conciliação entre estrutura e temática do poema. Esses elementos aparecem ajustados de forma precisa e calculada e articulam-se e interpenetram-se mutuamente. Quanto ao conjunto dos poemas analisados, procurou-se evidenciar que a busca pelo concreto justifica a atitude de ter a pedra como horizonte a ser atingido, sendo ela entendida como ápice de concretude e objetividade, qualidades estendíveis à composição cabralina que, para atingir tal propósito, necessita ser arquitetada matematicamente.

\section{Referências}

BONFAND, Alain. A arte abstrata. Campinas: Papirus, 1996. Tradução de Denise P. Lotito.

CAMPOS, Haroldo de. O geômetra engajado. In: Metalinguagem e outras metas. Petrópolis: Vozes, 1967. 
CAMPOS, Maria do Carmo (Org.). João Cabral em perspectiva. Porto Alegre: Editora da Universidade/ UFRGS, 1995.

MONDRIAN, Piet. Composition A: Composition with Black, Red, Gray, Yellow, and Blue, 1920. Oil on canvas. $91.5 \quad$ x $92 \quad \mathrm{~cm} \quad\left(\begin{array}{llllll}36 & \text { X } & 36 & 1 / 4 & \text { in })\end{array}\right.$ Galleria Nazionale d'Arte Moderna e Contemporanea, Rome. Disponível em: http://www.artchive.com/artchive/M/mondrian/mondrian_composition_a.jpg.html. Acesso em 07 out 2006.

MELO NETO, João Cabral. Obra completa: volume único; Organização de Marly de Oliveira. Rio de Janeiro: Nova Aguilar, 2003.

PEIXOTO, Marta. Poesia com coisas. São Paulo: Perspectiva, 1983. 